\title{
Controlling tip of nasotracheal tube under video laryngoscopy
}

\author{
Hong-Yong Jin ${ }^{1} \cdot$ Fu-Shan Xue ${ }^{2}$ Gui-Zhen Yang ${ }^{2}$
}

Received: 13 July 2016 / Accepted: 14 July 2016 / Published online: 25 July 2016

(C) Japanese Society of Anesthesiologists 2016

\section{To the Editor:}

We read with interest the case report by Arslan et al. [1] performing nasotracheal intubation using a video laryngoscope and Magill forceps in a patient with restricted mouth opening. Given that directing the tip of the nasotracheal tube into the glottis under video laryngoscopy can be challenging in patients with restricted mouth opening, their method has potential implications. As the authors mentioned, however, it is difficult to view the tip of the Magill forceps and hold the tip of the nasotracheal tube under video laryngoscopy, because the Magill forceps are straight and patients with restricted mouth opening have a limited space available for manipulating the Magill forceps. This not only makes use of the Magill forceps very awkward, but also could result in potential risks of upper airway trauma. Thus, in our practice, we prefer to use the cuff inflation method or a surgical suture fixed on the nasotracheal tube's tip to solve this difficulty.

When the nasotracheal tube's tip fails to align with the glottis under video laryngoscopy, the cuff is slowly inflated until the tube's tip is aligned with the glottis under direct vision on the monitor (Supplementary Figure 1A). After the tube has been advanced to pass the glottis, the cuff is deflated and the tube is inserted into the trachea. Use of a surgical suture to control the distal tip of the nasotracheal tube under video laryngoscopy has recently been reported by Hung et al. [2]. In our experience, this method is effective in correcting the posterior or lateral tube tip location (Supplementary Figure 1B).

\section{Compliance with ethical standards}

Conflict of interest All authors have no financial support and potential conflicts of interest for this work.

\section{References}

1. Arslan Zİ, Ozdal P, Ozdamar D, Agır H, Solak M. Nasotracheal intubation of a patient with restricted mouth opening using a McGrath MAC X-Blade and Magill forceps. J Anesth.

2. Hung KC, Hsieh SW, Liu PH. A novel method to control the distal tip of nasotracheal tube. J Clin Anesth. 2006;33:160-1.
Electronic supplementary material The online version of this article (doi:10.1007/s00540-016-2218-x) contains supplementary material, which is available to authorized users.

\footnotetext{
Fu-Shan Xue

xuefushan@aliyun.com; fushan.xue@gmail.com

1 Department of Anesthesiology, Beijing Sixth Hospital,

Beijing, People's Republic of China

2 Department of Anesthesiology, Plastic Surgery Hospital, Chinese Academy of Medical Sciences and Peking Union Medical College, 33 Ba-Da-Chu Road, Shi-Jing-Shan

District, Beijing 100144, People's Republic of China
} 